\title{
Chronic obstructive pulmonary disease in primary care: an epidemiologic cohort study from the Canadian Primary Care Sentinel Surveillance Network
}

\author{
Michael E. Green MD MPH, Nandini Natajaran MD, Denis E. O’Donnell MD, Tyler Williamson PhD, \\ Jyoti Kotecha MPA, Shahriar Khan MSc, Andrew Cave MB ChB MClSc
}

\section{Abstract}

Background: Chronic obstructive pulmonary disease (COPD) is mostly managed within primary care, but there is little Canadian evidence from this setting. This study was undertaken to determine the prevalence of physician-diagnosed COPD in primary care practices, and the degree of comorbidity with other chronic conditions, and to assess patterns of medication prescribing.

Methods: The Canadian Primary Care Sentinel Surveillance Network is a national "network of networks" whose member practices use electronic medical records (EMRs). At the time of the study, it included data from 444 physicians from 10 networks in 8 provinces. We conducted an epidemiologic cohort study of all patients who had EMR data collected by the network at the end of 2012. Validated case-finding algorithms were used to identify cases of COPD. We used descriptive statistics and multivariate modelling analyses to calculate the prevalence of COPD, its association with key demographic factors and comorbidities, and patterns of medication prescribing.

Results: The observed prevalence of COPD was 4.0\% (10 043/250 346), which represents a population prevalence of $3.4 \%$ using age-sex standardization. Comorbidity was common, with prevalence ratios ranging from 1.1 for the presence of a single comorbid condition to 1.9 for 4 or more comorbid conditions. Anticholinergic agents (63\%), short- (48\%) and long-acting (38\%) $\beta$-agonists and inhaled corticosteroids (41\%) were the most commonly used medications.

Interpretation: The prevalence of physician-diagnosed COPD in Canadian primary care practices was similar to that reported in other practice-based studies at about 3\%-4\%. Most patients had comorbid conditions and were taking multiple medications. EMR data may be useful to assess both the epidemiology and management of COPD in primary care practices.

hronic obstructive pulmonary disease (COPD) is a substantial source of morbidity and mortality in Canada and globally. Estimates place the worldwide prevalence at $9 \%-10 \%$ from physiologic-based studies and $3 \%-8 \%$ from studies based on physician- or patient-reported diagnosis or symptoms. ${ }^{1,2}$ Globally, COPD is rated as the fifth leading cause of death, and ninth in contributions to loss of disability-adjusted life years. ${ }^{3,4}$ A recent systematic review of COPD epidemiology worldwide identified 12 Canadian studies, which produced prevalence estimates that ranged from $3 \%$ to $12 \%$, depending on the method used. ${ }^{5}$ Canadian data from a study using spirometry to screen a populationbased sample suggest a rate of about $10 \% .^{6}$ There are limited data on COPD either alone or in combination with other chronic diseases from primary care settings.

In other countries, the limited reports on COPD prevalence in primary care settings show marked variation depending on the method of identification of illness. A study from the United Kingdom based on electronic records in the Computerized Patient Records Database found the prevalence of physician-diagnosed COPD to be less than $1 \%$ for women and only $1.35 \%$ for men. ${ }^{7}$ Another practice-based research network study from the UK that invited participants in a postal survey to come for spirometry if they had either symptoms or a smoking history found a much higher prevalence ( $4.1 \%$ overall, $9.6 \%$ in patients over $40 \mathrm{yr}$ ). ${ }^{8} \mathrm{~A}$ recent Spanish study using data from electronic medical records (EMRs) found a physician-diagnosed prevalence of $3.2 \%, 90 \%$ of whom were also found to have at least 1 comorbid condition. ${ }^{9}$

Competing interests: None declared.

Correspondence to: Michael Green, michael.green@dfm.queensu.ca CMAJ Open 2015. DOI:10.9778/cmajo.20140040 
Our current understanding of the extent of COPD in Canada and its impact on health and health systems is not based on primary care data, but is based on data from large population health surveys or from administrative data. ${ }^{10-12}$ However, COPD is primarily managed within the primary care sector. The Canadian Primary Care Sentinel Surveillance Network was established in 2008 to bring together practice-based research networks using diverse EMR systems to generate data on chronic disease in Canadian primary care settings. Chronic obstructive pulmonary disease is one of the 8 common chronic conditions targeted by the network. This study was undertaken to explore the prevalence of COPD, the degree of comorbidity with respect to the other conditions for which the Canadian Primary Care Sentinel Surveillance Network has validated algorithms, and common patterns of medication prescribing by primary care physicians in Canada.

\section{Methods}

\section{Data sources and study population}

The Canadian Primary Care Sentinel Surveillance Network is a national network of practice-based research networks whose member primary care practices use various EMRs. Its overall architecture and approach have been described in detail elsewhere. ${ }^{13,14}$ The Canadian Primary Care Sentinel Surveillance Network was initially developed by networking existing practice-based research networks affiliated with academic centres across the country. These networks then entered into a process of recruitment of additional practices to their networks. Initially, in most areas, this was done with a convenience sample of interested practices that used EMRs. More recently, focused recruitment has been employed to enhance the representativeness of the network. This study used data from the network extracted on Dec. 31, 2012. At that time, the network included data from 444 physicians in 10 networks covering 8 provinces of Canada using 12 different EMR systems. Case-finding algorithms have been established for 8 chronic diseases, including COPD, and validated against chart abstraction and physician identification of cases. ${ }^{15-17}$ For COPD, the algorithms of the Canadian Primary Care Sentinel Surveillance Network have a sensitivity of $82 \%$ and specificity of $97 \% .{ }^{16}$ Details of the case definitions and algorithms used are available on the network's website (cpcssn.ca/research-resources/case-definitions). This study population has been shown elsewhere to be reasonably representative of the primary care population in Canada. ${ }^{18}$ Patients under 18 years of age were excluded from this study.

The Health Sciences Research Ethics Board of Queen's University approved this study.

\section{Statistical analysis}

We used a combination of descriptive statistics and multivariate modelling for data analysis using SAS statistical software version 9.3. We first calculated the prevalence rates for COPD, classified by an appropriate age group and sex. We estimated the prevalence using the denominator described by Greiver and colleagues ${ }^{19}$ because it approximates the general population while the 24-month contact group approximates those attending the practice. We then calculated age- and sex-standardized prevalence rates according to Canadian national age and sex distribution (census 2011). ${ }^{20} \mathrm{We}$ then looked at the prevalence ratios by 3 risk factors: rural postal code of the clinic (second digit of the postal code being 0 ), ${ }^{21}$ body mass index categories (underweight: $<18.5$, normal weight: $18.5-24.9$, overweight: $25-29.9$ and obese $\geq 30$ ) and smoking (never, past, current).

Three separate regression analyses were carried out to calculate prevalence ratios, each controlling for age and sex of the study population. In addition, we looked at the cumulative proportion of patients diagnosed with 1 or more of the other conditions targeted by the network, with respect to the absence and presence of the index condition in question. Also, we calculated the average number of comorbid conditions by age group. Finally, we investigated the medication data by analyzing the pattern of medication use by those who were diagnosed with COPD. In this report, medication use for a particular medication means that there is at least 1 prescription for that medication somewhere in the patient's electronic medical record.

For dichotomous outcomes, we used a generalized linear model with a log link function and a binomial distribution. For count data, we used a log link function and the Poisson distribution, each fit using the SAS GENMOD procedure. This procedure uses a generalized estimating equation approach for estimation of regression parameters. Along with prevalence ratios, the corresponding $95 \%$ confidence intervals (CIs) are reported, using the same approach.

\section{Results}

The characteristics of the study population are presented in Table 1.

Table 2 and Figure 1 present the age and sex distribution of our sample population and the prevalence of COPD. The overall observed prevalence is $4.0 \%$, which represents a prevalence of $3.4 \%$ using standard age and sex standardization or $3.2 \%$ using the general population denominator of the Canadian Primary Care Sentinel Surveillance Network. Diagnosis of COPD was associated with rural residence (prevalence ratio $1.22,95 \%$ CI 1.17-1.28), current (prevalence ratio 7.09, 95\% CI 7.3-8.5) and past (prevalence ratio 3.25, 95\% CI 3.01-3.51) smoking, and weight category other than normal (underweight: prevalence ratio $1.35,95 \%$ CI 1.1.21-1.50; overweight: prevalence ratio $0.90,95 \%$ CI $0.85-0.96$; obese: prevalence ratio $1.17,95 \%$ CI 1.10-1.23) (data not shown).

Information on comorbidity with other conditions targeted by the Canadian Primary Care Sentinel Surveillance Network is presented in Tables 3 and 4, and Figure 2. Table 3 presents the prevalence ratios for the presence of the other chronic diseases identified by the network for patients with a diagnosis of COPD in comparison to those without COPD. Patients with COPD are more likely to receive a diagnosis of every other comorbidity except Parkinsonism. Table 4 reports the prevalence of comorbidities and the prevalence ratios for multimorbidity in patients with COPD as compared with other patients 
in the network with at least 1 chronic disease. Of all patients with COPD, $76.7 \%$ had 1 or more other chronic condition, and $3.2 \%$ had 4 or more other conditions. Prevalence ratios for comorbidity were all greater than 1, ranging from 1.12 for presence of 1 or more comorbid conditions to 1.9 for 4 or more conditions. Figure 2 shows the mean number of comorbid conditions and the prevalence ratios by age and sex for patients with COPD compared with other patients with chronic disease. Comorbidity is higher for COPD for all age groups with the prevalence ratio highest in the younger age groups and diminishing with increasing age.

Tables 5 and 6 present information on prescribed medications for treatment of COPD. Table 5 provides the prevalence of prescriptions for various therapeutic agents by class and drug. Table 6 presents data on the numbers of drug classes used, and Table 7 provides additional detail on the class combinations. Anticholinergics were the most commonly prescribed medications, followed by short-acting $\beta$-agonists, inhaled corticosteroids and long-acting $\beta$-agonists. Most patients were prescribed multiple medications.

\section{Interpretation}

In this study the estimated prevalence of COPD overall for adults in primary care practices was $3.4 \%$ using age-sex standardization. This is similar to the rate of $3.2 \%$ reported by García-Olmos and colleagues in a recent EMR-based study on primary care practices in Spain. ${ }^{9}$ It is lower than rates of $9 \%-10 \%$ expected based on population-based studies using physiologic measures. ${ }^{2,6,22}$ This difference is consistent with past studies that found COPD to be underdiagnosed or misdiagnosed quite frequently. Frank and colleagues ${ }^{23}$ found that less than half of patients with Global Obstructive Lung Disease categories $2-4$ by spirometry had a diagnosis of COPD recorded in their primary care medical records. Prevalence rates based on administrative data may be biased in the opposite direction. Lacasse and colleagues ${ }^{24}$ conducted a large validation of COPD

\begin{tabular}{|c|c|c|}
\hline \multirow[b]{2}{*}{ Characteristic } & \multicolumn{2}{|c|}{ No. (\%) of patients† } \\
\hline & $\begin{array}{c}\text { COPD } \\
n=10043 \dagger\end{array}$ & $\begin{array}{c}\text { No COPD } \\
n=240303+\end{array}$ \\
\hline Age, mean $\pm S D$ & $69.9(12.9)$ & $49.2(18.5)$ \\
\hline \multicolumn{3}{|l|}{ Sex } \\
\hline Male & 4649 (46.3) & 99533 (41.4) \\
\hline Female & $5394 \quad(53.7)$ & 140770 (58.6) \\
\hline Residence & $n=9794$ & $n=232685$ \\
\hline Urban & $6990 \quad(71.4)$ & $181086 \quad(77.8)$ \\
\hline Rural & $2804 \quad$ (28.6) & 51599 (22.2) \\
\hline \multicolumn{3}{|l|}{$\begin{array}{l}\text { No. of comorbid } \\
\text { conditions } \ddagger\end{array}$} \\
\hline 0 & 2338 (23.3) & 137110 \\
\hline 1 & 3549 (35.3) & 68297 (28.4) \\
\hline 2 & $2720 \quad(27.1)$ & 26299 (10.9) \\
\hline 3 & 1117 & $7147 \quad(3.0)$ \\
\hline$\geq 4$ & $319 \quad$ (3.2) & $1450 \quad(0.6)$ \\
\hline \multicolumn{3}{|c|}{$\begin{array}{l}\text { Note: } C O P D=\text { chronic obstructive pulmonary disease, } S D=\text { standard } \\
\text { deviation. } \\
\text { “Age } \geq 18 \text { yr. } \\
\text { †Unless stated otherwise. } \\
\text { łLimited to other conditions for which the Canadian Primary Care Sentinel } \\
\text { Surveillance Network has validated algorithms: hypertension, osteoarthritis, } \\
\text { diabetes mellitus, depression, epilepsy, Parkinson disease and dementia. }\end{array}$} \\
\hline
\end{tabular}

Table 2: Prevalence of chronic obstructive pulmonary disease, by patient age and sex*

\begin{tabular}{|c|c|c|c|c|c|c|}
\hline \multirow[b]{2}{*}{ Age group, yr } & \multicolumn{2}{|r|}{ Men } & \multicolumn{2}{|r|}{ Women } & \multicolumn{2}{|r|}{ Total } \\
\hline & $N$ & With COPD, no. (\%) & $N$ & With COPD, no. (\%) & $N$ & With COPD, no. (\%) \\
\hline $18-29$ & 17110 & $0(0.0)$ & 25626 & $0(0.0)$ & 42736 & $0(0.0)$ \\
\hline 30-39 & 14516 & $46(0.3)$ & 23839 & $72(0.3)$ & 38355 & $118(0.3)$ \\
\hline $40-49$ & 17508 & $240(1.4)$ & 24836 & $333(1.3)$ & 42344 & $573(1.4)$ \\
\hline $50-59$ & 20562 & $651(3.2)$ & 26812 & 890 (3.3) & 47374 & 1541 (3.3) \\
\hline $60-69$ & 17208 & $1213(7.0)$ & 20798 & $1291(6.2)$ & 38006 & 2504 (6.6) \\
\hline $70-79$ & 10446 & $1264(12.1)$ & 13316 & $1410(10.6)$ & 23762 & $2674(11.3)$ \\
\hline$\geq 80$ & 6832 & $1235(18.1)$ & 10937 & $1398(12.8)$ & 17769 & $2633(14.8)$ \\
\hline $\begin{array}{l}\text { All age } \\
\text { groups }\end{array}$ & 104182 & 4649 (4.5) & 146164 & 5394 (3.7) & 250346 & $10043(4.0)$ \\
\hline$\geq 40$ & 72556 & $4603(6.3)$ & 96699 & $5322(5.5)$ & 169255 & 9925 (5.9) \\
\hline$\geq 50$ & 55048 & 4363 (7.9) & 71863 & $4989(6.9)$ & 126911 & 9352 (7.4) \\
\hline
\end{tabular}


as recorded in administrative data from Quebec and found a diagnosis of COPD as the principal diagnosis for hospital discharges to have a positive predictive value of only $50.4 \%$ in identifying "true cases" as assessed by specialist physician review of hospital records. Gershon and colleagues ${ }^{25}$ also validated their administrative data definition of COPD against a chart review and found a sensitivity of $85 \%$ and specificity of $78.4 \%$ for the most inclusive definition, which they subsequently adopted, because more restricted definitions had poor sensitivity. In comparison, the Canadian Primary Care Sentinel Surveillance Network case-finding algorithm for COPD has a sensitivity of $82 \%$ while retaining a high specificity of $97 \% .{ }^{16}$ This may explain in part the significant differences between the rates observed in our data and the prevalence of almost $12 \%$ in adults over age 35 reported most recently by Gershon and colleagues. ${ }^{10,26}$ The true prevalence is likely found between these levels. A recent study by Muggah and colleagues ${ }^{27}$ also showed poor agreement between data from a large population health survey and the administrative data definition used in Ontario $(\kappa$ $=0.29$, prevalence $11.1 \%$ health administrative data, $5.6 \%$ selfreported). These large gaps highlight the issues raised by Manuel and colleagues ${ }^{28}$ and Green and colleagues ${ }^{29}$ on the importance of looking closely at the biases inherent in data sources when interpreting the results of even well-designed studies and surveillance systems that exploit our ability to access data that is generated during the provision of health care services. In our findings, the prevalence is similar for men and women in younger age categories, but significantly higher among men for all age groups over 60 years. This may be related to historical differences in smoking rates, in addition to other factors.

Levels of comorbidity were very high, with $76.7 \%$ of patients with COPD having at least 1 additional condition identified by the Canadian Primary Care Sentinel Surveillance Network. Real rates of comorbidity are likely even higher, because the network currently flags only a limited number of conditions. Comorbidity in patients with COPD was significantly higher than that experienced by other patients with chronic disease, particularly in younger patients. This is consistent with the limited number of prior studies on this issue that also found that most patients with COPD had other comorbid chronic conditions. ${ }^{2,30}$ For example, in the Spanish study that also used EMR data as a source and which included a much more comprehensive list of conditions, $90 \%$ of COPD patients had at least 1 comorbid condition. ${ }^{9}$ The higher prevalence ratio for comorbidities in the younger age groups would be consistent with the notion of distinct COPD "phenotypes," in which younger patients with more severe disease are one distinct type. ${ }^{31}$ This is particularly important for our conceptualization of COPD as an illness. It seldom occurs alone and should prompt a thorough assessment for the presence of other chronic conditions.

The current Canadian guidelines for management of COPD recommend anticholinergic medications or long-acting $\beta$-agonists, either alone or in combination, for patients with persistent symptoms. The addition of inhaled corticosteroid-long-acting $\beta$-agonist combination therapy to longacting anticholinergic therapy (i.e., triple therapy) should ideally be reserved for patients with moderate to severe airway obstruction who are prone to exacerbations. In selected patients who have persistent breathlessness despite optimal inhaled bronchodilators, a trial of oral theophyllines might be considered. Oral anti-inflammatory agents (e.g., roflumilast) may be appropriate in selected patients with a chronic bronchitis phenotype who are prone to exacerbations and

\begin{tabular}{|c|c|}
\hline Comorbidity* & $\begin{array}{c}\text { Adjusted prevalence } \\
\text { ratio }(95 \% \mathrm{Cl})\end{array}$ \\
\hline Hypertension & $1.09(1.07-1.11)$ \\
\hline Diabetes & $1.30(1.25-1.34)$ \\
\hline Depression & $1.68(1.62-1.74)$ \\
\hline Osteoarthritis & $1.19(1.15-1.23)$ \\
\hline Dementia & $1.11(1.03-1.19)$ \\
\hline Epilepsy & $1.68(1.43-1.98)$ \\
\hline Parkinsonism & $0.90(0.73-1.11)$ \\
\hline \multicolumn{2}{|c|}{$\begin{array}{l}\text { Note: } \mathrm{Cl}=\text { confidence interval. } \\
\text { *We modelled the probability of each of the } \\
\text { comorbid conditions, for which the predictor is } \\
\text { COPD (yes/no), along with age and sex. } \\
\text { Interpretation: People with COPD are } 1.09 \text { times as } \\
\text { likely to be hypertensive as people without COPD, } \\
\text { and so on. }\end{array}$} \\
\hline
\end{tabular}

Table 4: Age- and sex-adjusted prevalence of comorbidities in patients with and without chronic obstructive pulmonary disease and prevalence ratios for multimorbidity in patients with chronic obstructive pulmonary disease

\begin{tabular}{|c|c|c|c|}
\hline \multirow[b]{2}{*}{ Variable } & \multicolumn{2}{|c|}{ No. $(\%)$ of patients } & \multirow[b]{2}{*}{$\begin{array}{l}\text { Adjusted prevalence } \\
\text { ratio }(95 \% \mathrm{Cl})^{*}\end{array}$} \\
\hline & $\begin{array}{c}\text { COPD } \\
n=10043\end{array}$ & $\begin{array}{c}\text { No COPD } \\
n=103193\end{array}$ & \\
\hline COPD alone & 2338 (23.3) & - & - \\
\hline \multicolumn{4}{|c|}{ No. of comorbid conditions } \\
\hline$\geq 1$ & $7705(76.7)$ & $68297(66.2)$ & $1.12(1.10-1.13)$ \\
\hline$\geq 2$ & $4156(41.4)$ & $34896(33.8)$ & $1.31(1.27-1.34)$ \\
\hline$\geq 3$ & $1436(14.3)$ & $8597 \quad(8.3)$ & $1.61(1.53-1.70)$ \\
\hline$\geq 4$ & 319 (3.2) & 1450 & $1.90(1.67-2.15)$ \\
\hline \multicolumn{4}{|c|}{$\begin{array}{l}\text { Note: } \mathrm{COPD}=\text { chronic obstructive pulmonary disease. } \\
\text { *Poisson model: parameter estimates }(n=250346) \text {. Models included the predictor COPD (yes/no), along with age } \\
\text { and sex. Interpretation: Patients with COPD are } 1.12 \text { times as likely to have } 1 \text { or more other chronic conditions as } \\
\text { those without COPD, and so on. }\end{array}$} \\
\hline
\end{tabular}




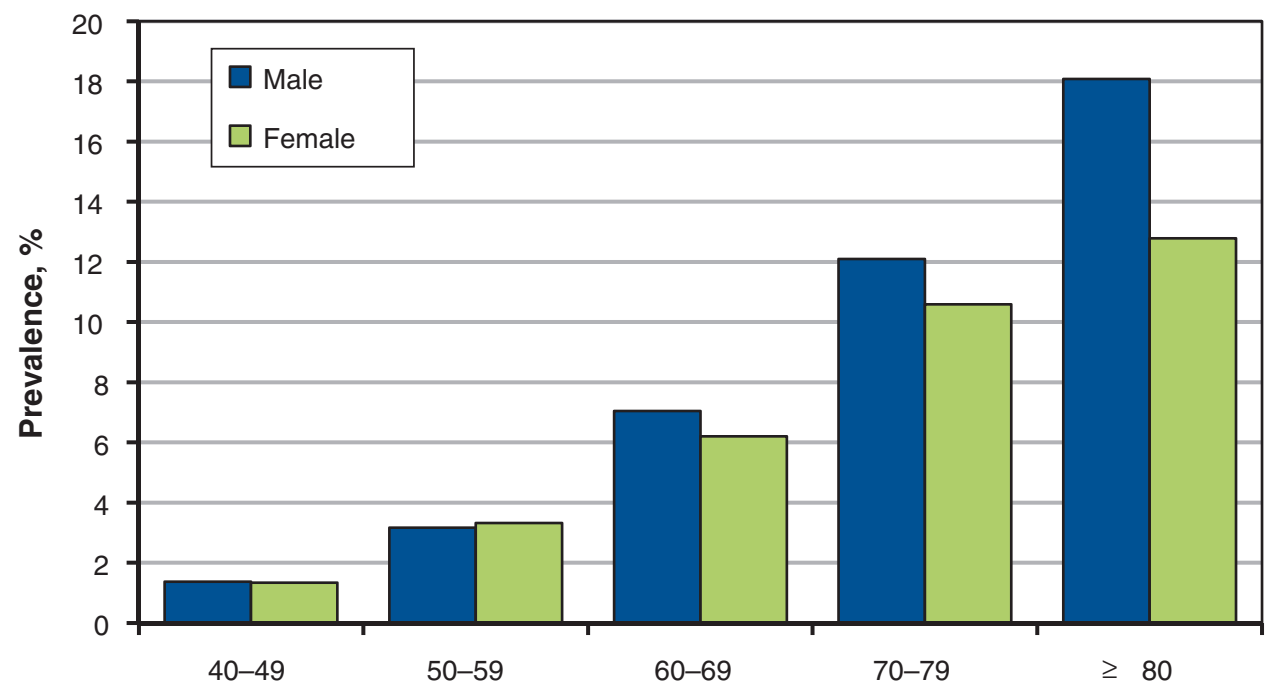

Age group, yr

Figure 1: Prevalence of chronic obstructive pulmonary disease (COPD) in patients aged 40 years and older. Data source: Canadian Primary Care Sentinel Surveillance Network 2012.

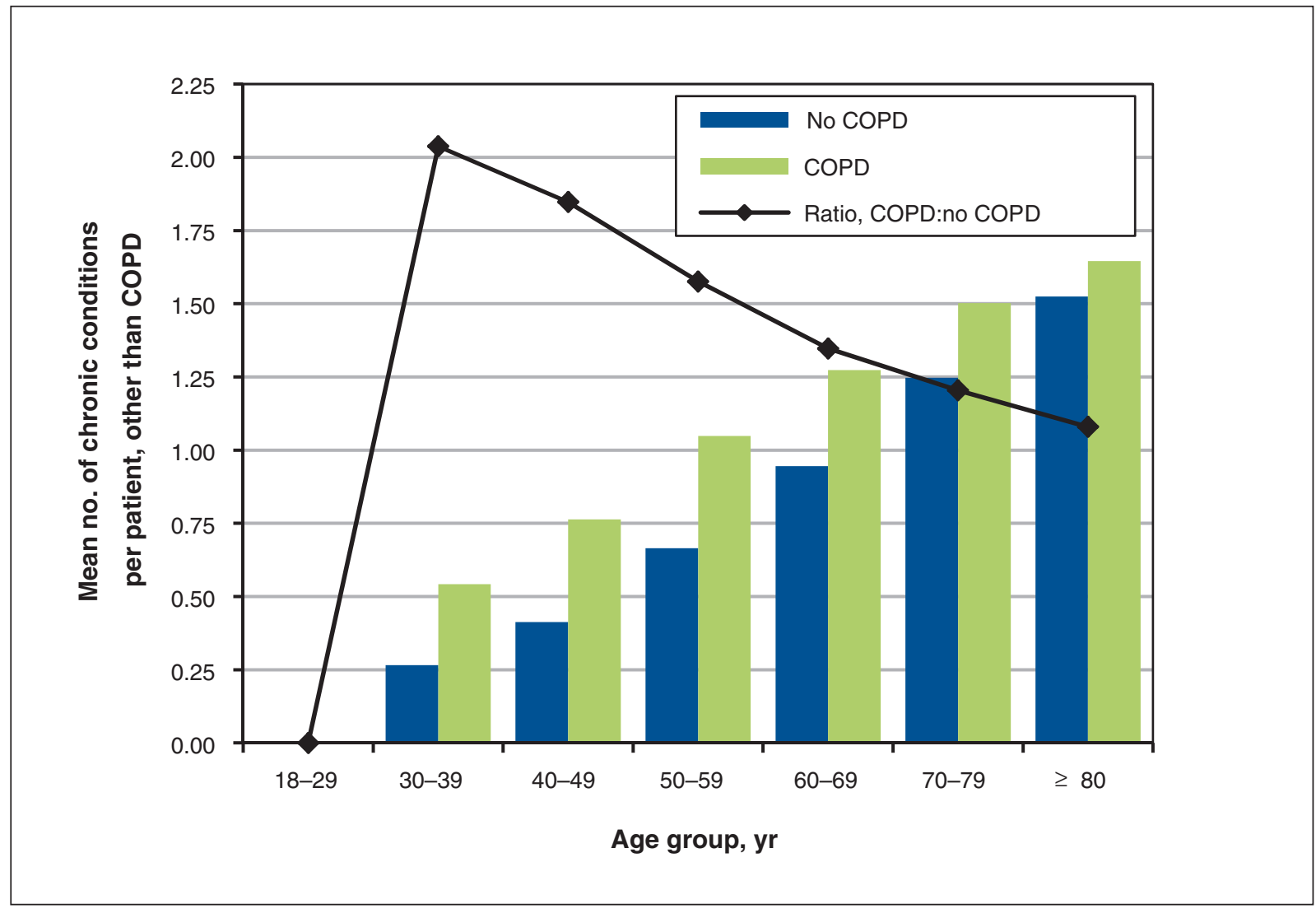

Figure 2: Mean number of comorbid conditions, by age and COPD status. The mean difference for each age group except 18-29 years is significant at $p<0.001$. Data source: Canadian Primary Care Sentinel Surveillance Network 2012. 
who have more advanced disease. ${ }^{32}$ Short-acting $\beta$-agonists are recommended as an adjunctive symptom-relieving medication in all patients taking anticholinergic agents who still have symptoms. In keeping with guidelines, we found that anticholinergic agents were the most commonly prescribed medications and were also most likely to be used alone. A relatively small proportion of patients were prescribed only inhaled corticosteroids (10\%) or short-acting $\beta$-agonists (7\%), which would not be concordant with current COPD guidelines. This pattern of medication use would be consistent with asthma guidelines and raises the possibility that some patients with asthma were misclassified here as having COPD. Most patients were taking 2 or more classes of medications. This would be consistent with having physiciandiagnosed COPD, which one would expect to be identified due to the presence of symptoms.

\section{Limitations}

One important limitation in our approach to using EMR data is that some information may not be accessible to the automated extraction processes used by the network (e.g., image files, scanned reports such as pulmonary function tests or radiology reports, and free-text fields). In addition, the Canadian Primary Care Sentinel Surveillance Network is a voluntary network of primary care providers in Canadian primary care practices and thus may not be fully representative of the full range of patients and providers. However, the overall age-sex distribution of the network's patients is comparable to national averages and adjustment measures have been used to account for this when estimating prevalence. ${ }^{18}$ With respect to the reporting of comorbidities, the network currently has validated algorithms for only 8 conditions, so reporting is limited to these at the present time. For example, cardiovascular disease is a well-known comorbidity, but there is currently no validated algorithm for this. There is, however, a plan to develop one in the future. There is also no currently validated algorithm for asthma, which may result in misclassification of some patients with asthma as having COPD. This may account for the identification of medication-use patterns in some patients that is more consistent with asthma than with COPD. We relied on physician diagnosis for COPD, which may or may not include spirometry for confirmation. This could lead to misclassification of patients who have other pulmonary conditions. Finally, for the medication-use data, the use of a single prescription for a medication as the criterion will most likely result in overcounting of medications, because medications that are not renewed, currently active or not filled by the patient will be counted. This will be counterbalanced to some degree by prescriptions from external providers such as specialist physicians and hospitals that may not be recorded in the primary care EMR.

\section{Conclusion}

We found the prevalence of physiciandiagnosed COPD in Canadian primary care practices identified by the algorithms of the Canadian Primary Care Sentinel Surveillance Network to be similar to

\begin{tabular}{|lc|}
\hline $\begin{array}{l}\text { Table 6: Use of multiple classes of } \\
\text { medication }\end{array}$ \\
\hline $\begin{array}{l}\text { No. of other } \\
\text { classes }\end{array}$ & $\begin{array}{c}\text { No. (\%) of patients } \\
n=10043\end{array}$ \\
\hline 0 & $1687^{*}(16.8)$ \\
\hline 1 & $2090(20.8)$ \\
\hline 2 & $2643(26.3)$ \\
\hline 3 & $2329(23.2)$ \\
\hline$\geq 4$ & $1294(12.9)$ \\
\hline $\begin{array}{l}\text { Note: COPD = chronic obstructive pulmonary } \\
\text { disease. } \\
* \text { Of } 1687 \text { patients with COPD, } 1372(81.3 \%) \\
\text { were taking non-COPD medications and } 315 \\
(18.7 \%) \text { were not taking any medications. }\end{array}$ \\
\hline
\end{tabular}


Table 7: Use of multiple classes of medication, additional details

\begin{tabular}{|c|c|c|c|c|c|c|}
\hline \multirow{2}{*}{$\begin{array}{l}\text { No. of } \\
\text { other } \\
\text { classes }\end{array}$} & \multicolumn{6}{|c|}{$\%$ of patients } \\
\hline & $\begin{array}{l}\text { Anticholinergics } \\
\quad n=6323\end{array}$ & $\begin{array}{c}\text { ICS } \\
n=4080\end{array}$ & $\begin{array}{c}\text { LABA } \\
n=3838\end{array}$ & $\begin{array}{c}\text { SABA } \\
n=4829\end{array}$ & $\begin{array}{c}\text { Theophyllines } \\
n=172\end{array}$ & $\begin{array}{l}\text { Other* } \\
n=487\end{array}$ \\
\hline 0 & 16.4 & 10.1 & 7.3 & 7.2 & 2.3 & 2.7 \\
\hline$\geq 1$ & 83.6 & 89.9 & 92.7 & 92.8 & 97.7 & 97.3 \\
\hline$\geq 2$ & 53.2 & 60.6 & 70.3 & 66.9 & 93.6 & 87.7 \\
\hline$\geq 3$ & 19.9 & 28.5 & 32.2 & 25.7 & 83.1 & 66.1 \\
\hline
\end{tabular}

prevalence reported in other practice-based studies at about $3 \%-4 \%$. When compared with rates of about $10 \%$ suggested by population-based samples tested by spirometry, this suggests that underdiagnosis remains an important issue. Targeted spirometry screening for people who smoke who are at risk of COPD is one strategy that could be considered to improve this. Compared with other data sources such as administrative databases or population-based surveys, EMR data has the potential to provide more specific estimates without compromising sensitivity and to provide more complete information on treatment practices. Comorbidity is extremely common, with most patients having at least one additional condition. Patterns of medication prescribing were roughly aligned with current guidelines, but a more detailed analysis of medication combinations would be required to adequately assess this fully.

\section{References}

1. Buist AS, Vollmer WM, McBurnie MA. Worldwide burden of COPD in high- and low-income countries. Part I. the burden of obstructive lung disease (BOLD) initiative. Int 7 Tuberc Lung Dis 2008;12:703-8.

2. Halbert RJ, Natoli JL, Gano A, et al. Global burden of COPD: systematic review and meta-analysis. Eur Respir 7 2006;28:523-32.

3. Murray CJL, Abdalla S, Dharmaratne SD, et al. Disability-adjusted life years (DALYs) for 291 diseases and injuries in 21 regions, 1990-2010: a systematic analysis for the global burden of disease study 2010. Published erratum in Lancet 2013;381:628]. Lancet 2012;380:2197-223.

4. Pauwels RA, Rabe KF. Burden and clinical features of chronic obstructive pulmonary disease (COPD). Lancet 2004;364:613-20.

5. Rycroft CE, Heyes A, Lanza L, et al. Epidemiology of chronic obstructive pulmonary disease: a literature review. Int 7 Chron Obstruct Pulmon Dis 2012;7:457-94

6. Raghavan N, Lam YM, Webb KA, et al. Components of the COPD Assessment Test (CAT) associated with a diagnosis of DOPD in a random population sample. COPD 2012;9:175-83.

7. Soriano JB, Maier WC, Egger P, et al. Recent trends in physician diagnosed COPD in women and men in the UK. Thorax 2000;55:789-94.

8. Frank TL, Hazell ML, Linehan MF, et al. The estimated prevalence of chronic obstructive pulmonary disease in a general practice population. Prim Care Respir 7 2007;16:169-73.

9. García-Olmos L, Alberguilla A, Ayala V, et al. Comobidity in patients with chronic obstructive pulmonary disease in family practice: a cross sectional study. BMC Fam Pract 2013;14:11.

10. Gershon AS, Wang C, Wilton A, et al. Trends in chronic obstructive pulmonary disease prevalence, incidence, and mortality in Ontario, Canada, 1996 to 2007. Arch Intern Med 2010;170:560-5.

11. Camp PG, Chauhdry M, Platt H, et al. The sex factor: epidemiology and management of chronic obstructive pulmonary disease in British Columbia. Can Respir 7 2008;15:417-22.

12. Life and breath: respiratory disease in Canada. Ottawa: Public Health Agency of Canada; 2008. Available: www.phac-aspc.gc.ca/publicat/2007/lbrdc-vsmrc /index-eng.php (accessed 2014 Oct. 23).
13. Birtwhistle R, Keshavjee K, Lambert-Lanning A, et al. Building a pan-Canadian primary care sentinel surveillance network: initial development and moving forward. 7 Am Board Fam Med 2009;22:412-22.

14. Birtwhistle RV. Canadian Primary Care Sentinel Surveillance Network: a developing resource for family medicine and public health. Can Fam Physician 2011;57:1219-20

15. Kadhim-Saleh A, Green ME, Williamson T, et al. Validation of the diagnostic algorithms for five chronic conditions in the Canadian Primary Care Sentinel Surveillance Network. 7 Am Board Fam Med 2013;26:159-67.

16. Williamson T, Green ME, Birtwhistle RV, et al. Expanding opportunities for using electronic medical record data: validation of eight case definitions for chronic disease surveillance in the Canadian Primary Care Sentinel Surveillance Network database. Ann Fam Med 2014;12:367-72.

17. Natarajan N, Varatharasan N, Sabri S, et al. Is chart abstraction sufficient or is the "gold standard" of physician diagnosis needed when validating EMR case detection algorithms? [poster]. 2013 North American Primary Care Research Group (NAPCRG) annual meeting.2013 Nov. 21-25; Ottawa.

18. Williamson T, Lambert-Lanning A, Martin K, et al. Primary bealth care intelligence: 2013 progress report of the Canadian Primary Care Sentinel Surveillance Network (CPCSSN). Ottawa: CPCSSN; 2013.

19. Greiver M, Williamson T, Bennett TL, et al. Developing a method to estimate practice denominators for a national Canadian electronic medical record database. Fam Pract 2013;30:347-54.

20. 2011 census of population. Ottawa: Statistics Canada; 2011. Cat. no. 98-311-XCB2011018.

21. du Plessis V, Beshiri R, Bollman RD, et al. Definitions of rural. agriculture and rural working paper series working paper no. 61. Ottawa: Statistics Canada; 2002.

22. Evans J, Chen U, Camp PG, et al. Estimating the prevalence of COPD in Canada: Reported diagnosis versus measured airflow obstruction. Health Rep 2014;25:3-11.

23. Frank TL, Frank PI, Hazell ML, et al. The diagnostic accuracies of chronic obstructive pulmonary disease (COPD) in general practice: the results of the MAGIC (Manchester Airways Group Identifying COPD) study. Prim Care Respir 7 2006;15:286-93.

24. Lacasse Y, Daigle J, Martin S, et al. Validity of chronic obstructive pulmonary disease diagnoses in a large administrative database. Can Respir 7 2012; 19:e5-9.

25. Gershon AS, Wang C, Guan J, et al. Identifying individuals with physician diagnosed COPD in health administrative databases. COPD 2006;6:388-93.

26. Gershon AS, Guan J, Victor JC, et al. Quantifying health services use for chronic obstructive pulmonary disease. Am 7 Respir Crit Care Med 2013; 187:596-601.

27. Muggah E, Graves E, Bennett C, et al. Ascertainment of chronic diseases using population health data: a comparison of health administrative data and patient self-report. BMC Public Health 2013;13:16.

28. Manuel DG, Rosella LC, Stukel TA. Importance of accurately identifying chronic disease in studies using electronic health records. $B M 72010$; 341:c4226.

29. Green ME, Hogg W, Johnston S, et al. Assessing methods for measurement of clinical outcomes and performance in primary care practices. BMC Health Serv Res 2012;12:214.

30. van der Molen T. Comorbidities of COPD in primary care: frequency, relation to COPD, and treatment consequences. Prim Care Respir 7 2010;19:326-34.

31. Burgel PR, Paillasseur JL, Roche N. Identification of clinical phenotypes using cluster analysis in COPD patients with multiple comorbidities. BioMed Res Int 2014;2014:420134.

32. O'Donnell DE, Hernandez P, Kaplan A, et al. Canadian Thoracic Society Guidelines for the management of chronic obstructive pulmonary disease 2008 update - highlights for primary care. Can Respir 7 2008;15(Suppl A): $1 \mathrm{~A}-8 \mathrm{~A}$. 
Affiliations: Centre for Studies in Primary Care (Green, Williamson, Kotecha), Department of Family Medicine, Queen's University, Kingston, Ont.; Department of Public Health Sciences (Green), Queen's University, Kingston, Ont; Department of Family Medicine (Natajaran), Dalhousie University, Halifax, NS; Division of Respiratory and Critical Care Medicine (O'Donnell, Khan), Department of Medicine, Queen's University, Kingston, Ont.; Department of Family Medicine (Cave), University of Alberta, Edmonton, Alta.

Competing interests: Andrew Cave has received honoraria for membership of an advisory committee for AstraZeneca. No other competing interests were declared.

Contributors: This project was prepared by the authors on behalf of the Canadian Primary Care Sentinel Surveillance Network. Michael Green, Tyler Williamson, and Nandini Natajaran participated in the development and validation of the network algorithms. All authors participated in the development of the protocol for this study, analysis and interpretation of results and revisions and approval of the manuscript. Michael Green drafted the manuscript. Andrew Cave and Denis O'Donnell provided con- tent-specific expertise on chronic obstructive pulmonary disease. Michael Green, Tyler Williamson, Shahriar Khan, Nandini Natajaran and Jyoti Kotecha provided expertise in the areas of primary care and use of data from the Canadian Primary Care Sentinel Surveillance Network. Data analysis was performed primarily by Tyler Williamson and Shahriar Khan.

Acknowledgements: The Canadian Primary Care Sentinel Surveillance Network is a committee of the College of Family Physicians of Canada and is funded through a contribution agreement with the Public Health Agency of Canada. The conclusions and opinions expressed in this article are those of the authors and not necessarily of the college or the agency. This article is written by the authors on behalf of the Canadian Primary Care Sentinel Surveillance Network and its members. The authors thank Rachael Morkem and the Centre for Studies in Primary Care staff for their assistance with the organization and support of the writing group.

Supplemental information: For reviewer comments and the original submission of this manuscript, please see www.cmajopen.ca /content/3/1/E15/suppl/DC1 